\title{
Characterization of Asphalt Binder and Photoproducts by Fourier Transform Ion Cyclotron Resonance Mass Spectrometry Reveals Abundant Water-Soluble Hydrocarbons
}

Sydney F. Niles ${ }^{\dagger, \ddagger}$, Martha L. Chacón-Patiño ${ }^{\ddagger}$, Samuel P. Putnam ${ }^{\S}$, Ryan P. Rodgers ${ }^{*, \dagger,}$, Alan G. Marshall ${ }^{*},, \neq$

$\dagger$ Department of Chemistry and Biochemistry, 95 Chieftain Way, Florida State University, Tallahassee, FL 32306. United States

¥Ion Cyclotron Resonance Program, National High Magnetic Field Laboratory, Florida State University, Tallahassee, FL, 32310. United States

sDepartment of Chemistry and Biochemistry, 631 Sumter Street, University of South Carolina, Columbia, SC 29208. United States

Submitted to Environ. Sci. \& Technol. (es-2020-02263v) 11 April, 2020

Revised manuscript submitted:

17 June, 2020

\section{Supporting Information}

1. (+) APPI analysis of virgin asphalt starting material Page S2

2. Heteroatom content of virgin asphalt, dark control, and irradiated asphalt samples

Page S3

3. Comparison of irradiated asphalt with dark control and virgin asphalt binder

Page S4

4. Comparison of virgin asphalt binder, irradiated asphalt, and water-solubles from asphalt irradiation

Page S4 
Figure S1 Virgin Asphalt Starting Material
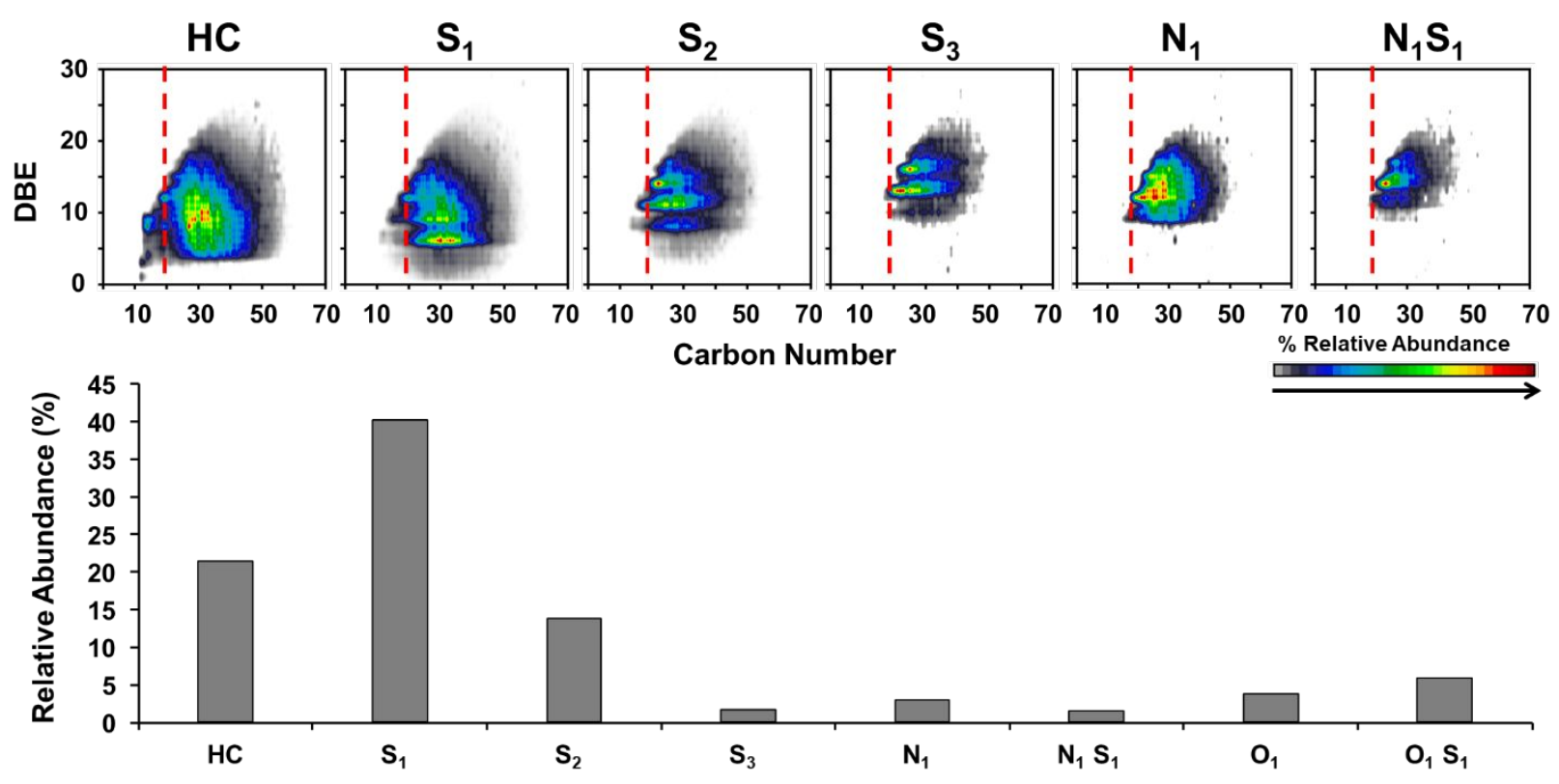

(+) APPI 9.4 Tesla FT-ICR MS Heteroatom Compound Class

Figure S1. DBE versus carbon number plots and heteroatom compound class distribution for (+) APPI FT-ICR MS analysis of virgin asphalt binder. 


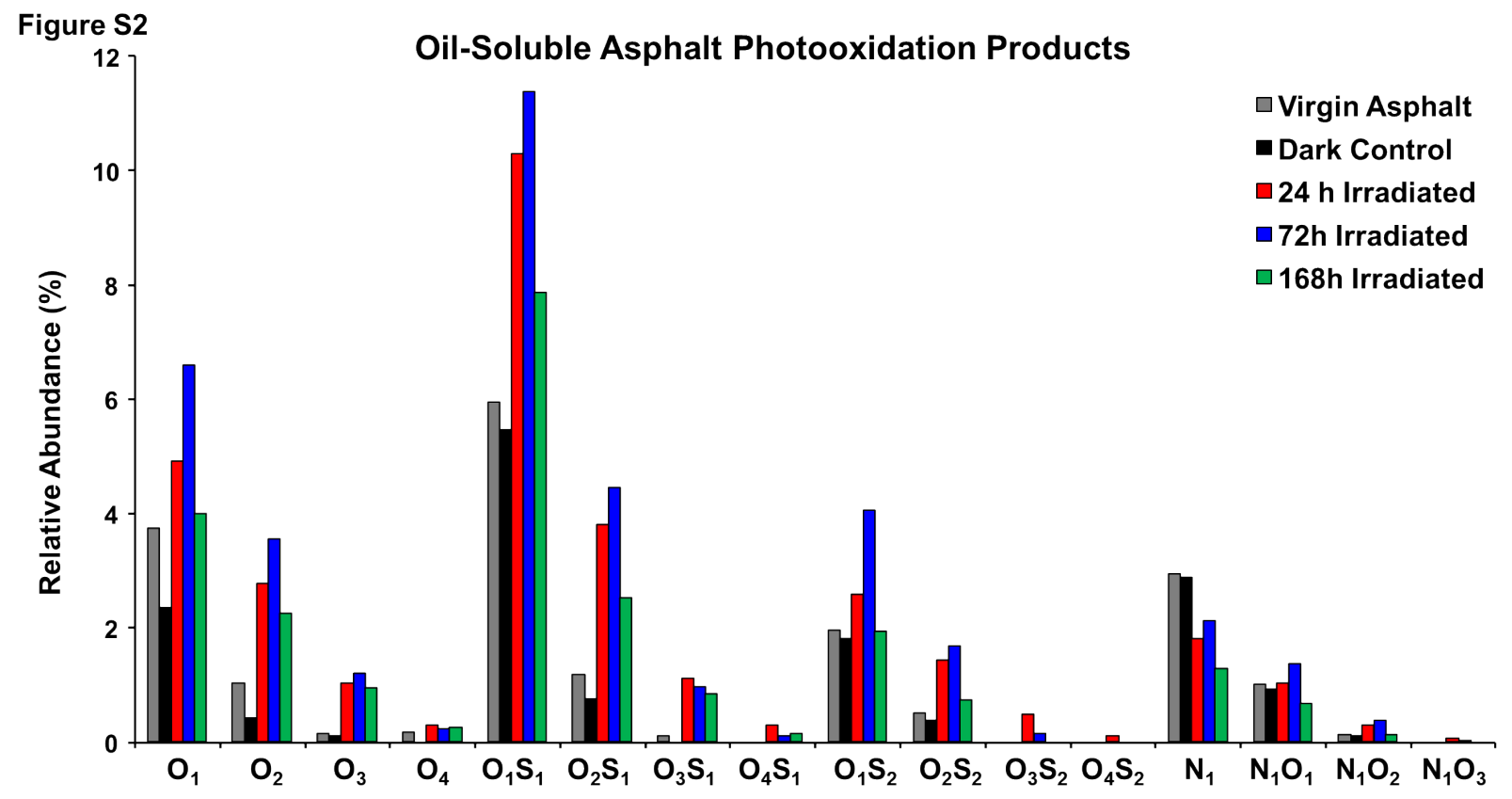

(+) APPI 9.4 Tesla FT-ICR MS Heteroatom Compound Class

Figure S2. Heteroatom compound class distribution for $(+)$ APPI FT-ICR MS analysis of virgin asphalt (gray), dark control (black), and $24 \mathrm{~h}$ (red), $72 \mathrm{~h}$ (blue), and $168 \mathrm{~h}$ (green) irradiated asphalt binder. 
Figure S3 Dark Control Comparison with Irradiated and Virgin Asphalt

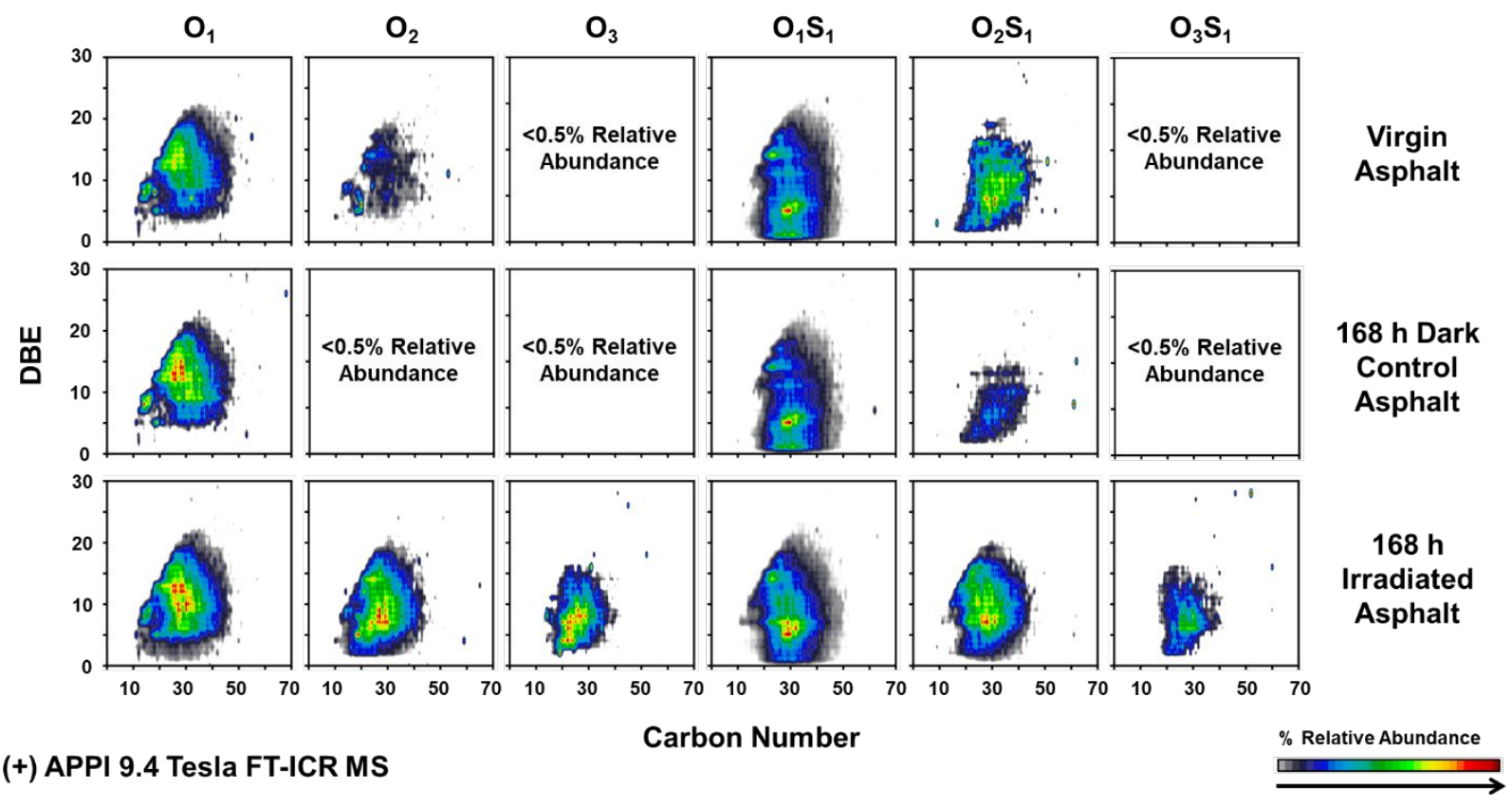

Figure S3. DBE versus carbon number plots for virgin asphalt binder, $168 \mathrm{~h}$ dark control, and $168 \mathrm{~h}$ irradiated asphalt binder.

Figure $S_{4} \quad$ Generation of Oil-Soluble $O_{x} S_{1}$ Species from Asphalt

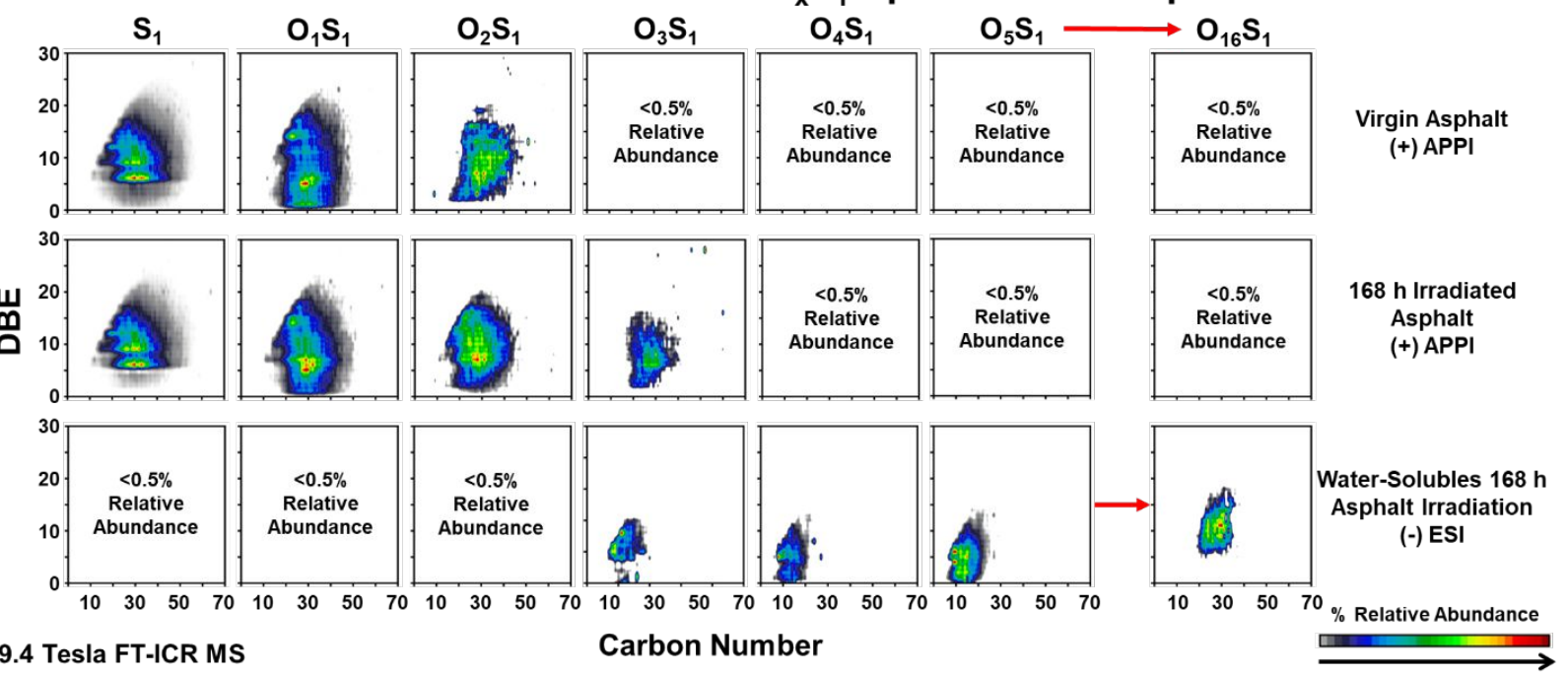

Figure S4. DBE versus carbon number plots for virgin asphalt, 168 $\mathrm{h}$ irradiated asphalt, and water-soluble photoproducts from $168 \mathrm{~h}$ irradiation of asphalt. 